\title{
Family interventions in early psychosis: specificity and effectiveness
}

\author{
J. Onwumere ${ }^{1 *}$, P. Bebbington ${ }^{2}$ and E. Kuipers ${ }^{1}$ \\ ${ }^{1}$ Department of Psychology, Institute of Psychiatry at King's College London, PO Box 77, Henry Wellcome Building, London SE5 8AF, UK \\ 2 Department of Mental Health Sciences, University College London, Bloomsbury Campus, 67-73 Riding House Street, 2nd Floor, Charles Bell \\ House, London W1W 7EJ, UK
}

\begin{abstract}
The first episode of psychosis frequently occurs during adolescence and early adulthood, and is associated with high levels of trauma, affective disturbance and suicide. The social networks of service users often decrease significantly following the first onset, although many will remain in close contact with some family members particularly during the early phases. However, the negative impact of psychosis on families and their relationship with the identified service user are well documented. Family intervention is a recommended and evidence-based treatment in later psychosis. In this paper, we review the literature on family interventions in early psychosis in the context of new evidence for its efficacy and its routine incorporation in early intervention services for psychosis.
\end{abstract}

\section{Background}

Schizophrenia spectrum psychoses rank among the most disabling conditions of modern times (World Health Organisation, 2001). The personal and financial costs are considerable and well documented (Knapp, Mangalore \& Simon, 2004). The first episode of psychosis frequently occurs during adolescence and early adulthood with an average delay of 22 weeks to 3 years before individuals begin formal treatment (Norman \& Malla, 2001; Stefan, Travis \& Murray, 2002; Norman et al. 2004). The initial episode, including the period of untreated illness, often coincides with a time when individuals are already encountering changes in their role and peer relationships, and are negotiating transitions to independence and responsibility (Mackrell \& Lavender, 2004).

\section{A critical period - the first 5 years}

For service users, the onset of psychosis is commonly associated with a broad range of feelings, including shock, confusion, fear, distress and despair. The literature suggests that the first 5 years constitute a critical period for treatment and outcomes (Birchwood, Todd \& Jackson, 1998; Lieberman \& Fenton, 2000). We know, for example, there are high levels of trauma, depression and anxiety in people presenting to early psychosis services (Koreen et al. 1993; Birchwood, Spencer \& McGovern, 2000; Birchwood, 2003; Mueser

* Address for correspondence: Dr J. Onwumere, Department of Psychology, Institute of Psychiatry at King's College London, PO Box 77, London SE5 8AF, UK.

(Email juliana.1.onwumere@kcl.ac.uk)
\& Rosenberg, 2003; Jackson et al. 2004). Suicide levels are elevated in psychosis, but particularly so in the early illness years (Caldwell \& Gottesman, 1990; Robinson et al. 2010). Aggressive behaviour is common, with recent figures suggesting that about $40 \%$ of service users engage in aggressive acts at first episode (Dean et al. 2006). Rates of co-morbid substance abuse disorders and problematic drug misuse are also high in first-episode groups (Green et al. 2004; Van Mastright et al. 2004; Lambert et al. 2005). In contrast, adherence to prescribed pharmacological treatments is poor (Coldham, Addington \& Addington, 2002). While remission from positive symptoms is often rapidly achieved following the first episode (Lieberman et al. 2003; Schooler et al. 2005), social dysfunction is a significant issue from the very early phases (Addington et al. 2008). Service users tend to become isolated very quickly after onset and their social contacts may become restricted to paid mental health professionals and a few close family members (Macdonald, Hayes \& Baglioni, 2000; Macdonald, Sauer, Howie \& Albiston 2005; Horan et al. 2006; Berry, Wearden \& Barrowclough, 2007; Stanghellini \& Ballerini, 2007).

\section{Effects on families}

A large body of literature confirms that the negative impact of psychosis extends beyond the service user; families are also adversely affected. In general, many service users maintain regular contact with their families. This is the case particularly during the early phase, when they are more likely to be living with their families of origin (Fisher et al. 2008). During this period, families play an active and key role in ensuring 
the care, well-being and recovery of service users. At the onset, they are often instrumental in initiating treatments and in helping the service user to engage with services and interventions (de Haan et al. 2002). However, the early illness phase can be a particularly challenging period for families as they struggle to make sense of the problems faced by their relative, including odd, unusual and embarrassing behaviours that may not always seem to be illness related. Carers spend a lot of time worrying about their relatives' well-being and future care (Tennakoon et al. 2000; Barker, Lavender \& Morant, 2001). They often face uncertainty about diagnosis, prognosis and the effectiveness of specific treatments. In addition, families must also adjust quickly to their new and unexpected role as 'caregiver', for which they often feel ill equipped and unprepared (Addington \& Burnett, 2004; Bergner et al. 2008). Carers rarely 'choose' their new role (Kuipers, 2001; Sawatzky \& Fowler-Kerry, 2003). Psychosis often has a deleterious effect on the social networks of carers, rendering them isolated and lonely, with feelings of stigmatization, particularly if their relative has been involved in antisocial behaviour (MacInnes, 2000; Ferriter \& Huband, 2003; Magligano et al. 2005). It is not surprising, therefore, that research over a 50-year period has shown that carers are negatively affected by their role, with as many as $80 \%$ reporting a sense of burden and distress (Magliano et al. 2002; Kuipers \& Bebbington, 2005; Parabiaghi et al. 2007). Indeed, at least one-third of carers are clinically depressed (Dyck, Short \& Vitaliano, 1999; Kuipers \& Raune, 2000; Lowenstein, Butler \& Ashcroft, 2010). Compared with those faced with the effects of more established illnesses, the carers of people attending early psychosis services tend to report equivalent or higher levels of distress and lower levels of positive caregiving experiences (Addington et al. 2003; Onwumere et al. 2008). Such carers often report levels of loss and grief similar to those seen in physical bereavement (Patterson, Birchwood \& Cochrane, 2005). Many mourn the loss of their relationship with the service user and of their plans for the future. They report feelings of guilt and blame for various reasons, for example, feeling that they failed to help their relative soon enough, that they missed key signs and symptoms indicative of illness, and even that they played a role in causing the illness (McCann et al. 2009). Sadly, as part of their role, many carers experience verbal and physical aggression (Loughland et al. 2009). Almost 25\% of homicides occur during the first episode, with close family members, particularly females, most likely to be victims (Nordstrom \& Kullgren, 2003a, $b$; Nielssen \& Large, 2010). Approximately one-third of carers report reactions indicative of post traumatic stress disorder (PTSD) (Barton \& Jackson, 2008; Loughland et al. 2009). We know that early psychosis carers are likely to have limited previous experience of mental health. One consequence is that carers often engage in less adaptive (avoidant) styles of coping, in themselves, associated with impact of care and poorer outcomes (Raune, Kuipers \& Bebbington. 2004; Onwumere et al. in press). Moreover, indices of strained family relations, identified in terms of highexpressed emotion, are already present in at least $50 \%$ of first episode carers (Bachmann et al. 2002; Raune et al. 2004). In summary, service users and their families have considerable and varied needs during the early phases.

\section{Family interventions}

Given the ubiquitous negative impact of psychosis on service users and their families, and the evidence for a critical early period, international clinical guidelines recommend family-focused interventions during the early illness phases (International Clinical Practice Guidelines for Early Psychosis, 2005), as delivered by specialist early intervention teams such as the flagship services in Melbourne, Birmingham, London and Calgary. The exact format and approach varies, but evidence-based family interventions include psychoeducation, stress reduction, emotional processing, cognitive reappraisal and structured problem solving. These are designed to support family carers in their role, improve adaptive coping and minimize the risk of relapse and readmission (Falloon, Boyd \& McGill, 1984; Barrowclough \& Tarrier, 1992; Kuipers, Leff \& Lam, 2002; Addington et al. 2005; Bertolote \& McGorry, 2005).

Overall, the evidence for the efficacy of family interventions is strong, with more than 50 controlled trials that have assessed service user outcomes (Cuijpers, 1999; Pilling et al. 2002; NICE Schizophrenia Update, 2009; Pharoah et al. 2010, 2009). Family interventions can be cost effective (Mihalopoulos et al. 2004). They significantly reduce rates of readmission and relapse in service users, and improve their social functioning (Pharoah et al. 2010). The interventions have been linked to improved adherence with pharmacological interventions (Mari \& Streiner, 1994; Pilling et al. 2002). In terms of carer outcomes, we also know that family interventions improve the experience of care and the commitment to the caregiving role (Berglund, Vahlne \& Edman, 2003; Giron et al. 2010).

It is clear that family intervention is effective. However, very few of the controlled trials have involved patients in the early stages of psychosis, and results have so far been equivocal. Moreover, 
where studies have been undertaken, family interventions have not been assessed independently. Thus, they have tended to be evaluated as part of an integrated approach to early intervention, making it difficult to assess the specific contribution of family intervention to service user and carer outcomes (e.g. Grawe et al. 2006). In a widely cited study, Linszen et al. (1996) examined 76 first episode families in receipt of individual psychosocial interventions. They recorded no benefits on relapse rates in families who received an additional 18 sessions of a year-long behavioural family intervention. Disappointingly, families with low expressed emotion (EE) actually became worse following the intervention. However, 5-year follow-up data indicated that family interventions reduced the length of time service users spent in hospital when compared with the standard individual interventions (Lenior, Dingemans \& Linszen, 2001). In 106 families, Leavey et al. (2004) compared a brief, seven-session family intervention with standard care. The authors observed no differences between the two groups in readmission rates and carer satisfaction. In a study covering only male service users, Zhang et al. (1994) recorded positive effects of family interventions on relapse rates and social functioning over an 18-month follow-up, when compared with standard outpatient provision. Interestingly, a recent meta-analysis and systematic review demonstrated that family interventions in early psychosis significantly reduce relapse and readmission rates (Bird et al. 2010).

As there are still relatively few well-controlled randomized trials of family intervention in early psychosis, there is a clear need for additional studies (Askey et al. 2007, 2009; Alvarez-Jimenez et al. 2009). Further work is also required to identify the key mediators of change, and to determine the most effective format and timing of interventions. It is unclear as to whether concepts relevant to longer-term carers have similar weight in early psychosis. High EE, for example, has proved a useful framework for understanding relationships and is a robust predictor of poor functioning and relapse in longer-term groups (Bebbington \& Kuipers, 1994). It has therefore been an important target for family interventions (Kuipers et al. 2002). However, the role and predictive qualities of EE have been less clearly established in early psychosis (Butzlaff \& Hooley 1998). Recent evidence from Gleeson and colleagues suggest that following positive symptom remission, effective interventions offer a combination of individual cognitive behaviour therapy (CBT) for service users and family work for carers, and specifically target relapse prevention (Gleeson et al. 2009). However, there is a paucity of literature on whether interventions are more effective when offered to single families, to multiple families or to a combination.

\section{A cognitive model of caregiving in psychosis}

In our recent cognitive model of caregiving, we described the main types of caregiving relationships in psychosis and the proposed family interventions (Kuipers, Onwumere \& Bebbington, 2010). In a climate of limited resources and of training and implementation difficulties with clinicians (Fadden, 2006, Kuipers, 2007), it is important that services have clear methods for identifying those in need of family interventions in early psychosis. However, evidence on how families successfully adapt following the first episode remains limited (Gleeson et al. 2010).

\section{Triaged interventions?}

Our clinical observations would suggest that, similar to longer-term groups, not all early psychosis families need full family intervention, particularly as we know that offering intensive interventions when they are not indicated may be harmful (Linszen et al. 1996). Given the range of issues they report, it seems likely that some early psychosis families might require only lowintensity interventions. These might offer clear and flexible opportunities for psychoeducation and social support. In the future, they might also use internet facilities to enhance the information provided (e.g. mentalhealthcare.org.uk - a website for carers and friends of those with psychosis; Rotondi et al. 2010). In contrast, intensive interventions are probably most suitable for families where there were previous as well as ongoing difficult relationships or when service users have persisting symptoms or frequent relapses or when carers have complicated grief reactions (Kuipers et al. 2010). We have argued that it may well be helpful to offer carers an individualized support service in their own right, as they are a seriously neglected group with needs of their own (Kuipers 2010).

\section{Conclusions}

A large number of people in need of early intervention for psychosis will still be in contact with their family of origin. These families will be caught up in the caring role. As in families dealing with longer-term illness, there will be a variable range of issues, but grief, loss and shock are likely to be salient. Not all families will need intensive support, and in fact, this may be harmful to those who have good relationships and who intuitively cope well. However, there will always be some families whose problems are not easily resolved. We argue that all families need basic support, but not all will benefit from the intensive support found helpful for longer-term groups and recommended by 
schizophrenia treatment guidelines (e.g. NICE, 2009; PORT, 2009; Kreyenbuhl et al. 2010). Offering intensive intervention as part of routine care may be problematic, and is most likely to be resourced and available in early intervention teams. Family intervention in early psychosis may well be preventative, and may also improve engagement with services in the longer term (Bird et al. 2010). However, it seems unlikely that all families will need it: some may require only low-intensity intervention. Acknowledging this would ensure that the intensive form of family intervention is targeted at those who really need it.

In summary:

(1) Psychosis can have a negative impact on service users and their families, and this is evident during the early illness phases.

(2) We need to know more about what support is required in particular family circumstances.

(3) It is likely that tailoring support to the individual family's needs will maximize both therapeutic benefit and the use of resources.

(4) The rational deployment of family intervention resource is likely to form a major component of secondary prevention.

\section{Declaration of Interest}

None

\section{References}

Addington J, Burnett P (2004). Working with families in the early stages of psychosis. In Psychological Interventions for Early Psychosis (ed. JFM Gleeson and PD McGorry), pp. 99116. Wiley and Sons: Chichester.

Addington J, Coldham EL, Jones B, Ko T, Addington D (2003). The first episode of psychosis: the experience of relatives. Acta Psychiatrica Scandinavica 108, 285-289.

Addington J, Collins A, McCleery A, Addington D (2005). The role of family work in early psychosis. Schizophrenia Research 79, 77-83.

Addington J, Penn D, Woods SW, Addington D, Perkins DO (2008). Social functioning in individuals at clinical high risk for psychosis. Schizophrenia Research 99, 119-124.

Alvarez-Jimenez M, Parker AG, Hetrick SE, McGorry PD, Gleeson JF (2009). Preventing the second episode: a systematic review and meta-analysis of psychosocial and pharmacological trials in first-episode psychosis. Schizophrenia Bulletin doi: 10.1093/schbul/sbp129. [Epub ahead of Print]

Askey R, Gamble C \& Gray R (2007). Family work in first onset psychosis: a literature review. Journal of Psychiatric and Mental Health Nursing 14, 356-365.

Askey R, Holmshaw J, Gamble C, Gray R (2009). What do carers of people with psychosis need from mental health services? Exploring the views of carers, services and professions. Journal of Family Therapy 31, 310-331.

Bachmann S, Bottmer C, Jacob S, Klaua-Thomas K, Backentsrass M, Mund C, Renneberg B, Fieldler P, Schroder J (2002). Expressed emotion in relatives of first-episode and chronic patients with schizophrenia and major depressive disorder - a comparison. Psychiatry Research 112, 239-250.

Barker S, Lavender T, Morant N (2001). Client and family narratives on schizophrenia. Journal of Mental Health, 10, 199-212.

Barrowclough C, Tarrier N (1992). Families of Schizophrenic Patients: Cognitive Behavioural Intervention. Chapman and Hall: London.

Barton K, Jackson C (2008). Reducing symptoms of trauma among carers of people with psychosis: pilot study examining the impact of writing about caregiving experiences. Australian and New Zealand Journal of Psychiatry 42, 693-701.

Bebbington P, Kuipers L (1994). The predictive utility of expressed emotion in schizophrenia - an aggregate analysis. Psychological Medicine 24, 707-718.

Berglund N, Vahlne JO, Edman A (2003). Family intervention in schizophrenia - impact on family burden and attitude. Social Psychiatry and Psychiatric Epidemiology 38, 116-121.

Bergner E, Leiner AS, Carter T, Franz L, Thompson NJ, Compton MT (2008). The period of untreated psychosis before treatment initiation: a qualitative study of family members' perspectives. Comprehensive Psychiatry 49, 530-536.

Berry K, Wearden A, Barrowclough C (2007). Adult attachment styles and psychosis: an investigation of associations between general attachment styles and attachment relationships with specific others. Social Psychiatry and Psychiatric Epidemiology 42, 972-976.

Bertolote J, McGorry P (2005). Early intervention and recovery for young people with early psychosis: consensus statement. British Journal of Psychiatry 48 (Suppl.), 116-119.

Birchwood M (2003). Pathways to emotional dysfunction in first-episode psychosis. British Journal of Psychiatry 182, 373-375.

Birchwood M, Spencer E, McGovern D (2000). Schizophrenia: early warning signs. Advances in Psychiatric Treatment 6, 93-101.

Birchwood M, Todd P, Jackson C (1998). Early intervention in psychosis: the critical period hypothesis. International Clinical Psychopharmacology 13 (Suppl. 1), 31-40.

Bird V, Premkumar P, Kendall T, Whittington C, Mitchell J \& Kuipers E (2010). Early intervention services, cognitivebehavioural therapy and family intervention in early psychosis: systematic review. The British Journal of Psychiatry 197, 350-356.

Butzlaff RL, Hooley JM (1998). Expressed emotion and psychiatric relapse - a meta-analysis. Archives of General Psychiatry 55, 547-552.

Caldwell CE, Gottesman JI (1990). Schizophrenics kill themselves too: a review of risk factors for suicide. Schizophrenia Bulletin 16, 571-589. 
Coldham EL, Addington J, Addington D (2002). Medication adherence of individuals with a first episode of psychosis. Acta Psychiatrica Scandinavica 106, 286-290.

Cuijpers P (1999). The effects of family intervention on relatives' burden: a meta analysis. Journal of Mental Health $\mathbf{8}$, 275-285.

Dean K, Walsh E, Morgan C, Demaha A, Dazzan P, Morgan K, Lloyd T, Fearon P, Jones PB, Murray RM (2007). Aggressive behaviour at first contact with services; findings from AESOP first episode psychosis study. Psychological Medicine 37(4), 547-557.

de Haan L, Peters B, Dingemans P, Wouters L, Linszen D (2002). Attitudes of patients toward the first psychotic episode and the start of treatment. Schizophrenia Bulletin 28, 431-442.

Dyck DG, Short R, Vitaliano PP (1999). Predictors of burden and infectious illness in schizophrenia caregivers. Psychosomatic Medicine 61, 411-419.

Fadden G (2006). Training and disseminating family interventions for schizophrenia: developing family intervention skills with multi-disciplinary groups. Journal of Family Therapy 28, 23-38.

Falloon IRH, Boyd JL, McGill CW (1984). Family Care of Schizophrenia. Guildford: London.

Ferriter M, Huband N (2003). Experiences of parents with a son or daughter suffering from schizophrenia. Journal of Psychiatric and Mental Health Nursing 10, 552-560.

Fisher H, Theodore K, Power P, Chisholm B, Fuller J, Marlowe K, Aitchison KJ, Tanna R, Joyce J, Sacks M, Craig T, Johnson S (2008). Routine evaluation in first episode psychosis services: feasibility and results from the MiData project. Social Psychiatry and Psychiatric Epidemiology 43, 960-967.

Giron M, Fernandez-Yanez A, Maná-Alvarenga S, Molina-Habas A, Nolasco A, Gomez-Beneyto M (2010). Efficacy and effectiveness of individual family intervention on social and clinical functioning and family burden in severe schizophrenia: a 2-year randomized controlled study. Psychological Medicine 40, 73-84.

Gleeson JF, Cotton SM, Alvarez-Jimenez M, Wade D, Gee D, Crisp K, Pearce T, Newman B, Spiliotacopoulos D, Castle D, McGorry PD (2009). A randomised controlled trial of relapse prevention therapy for first episode psychosis patients. Journal of Clinical Psychiatry $\mathbf{7 0}$ (4):477-486.

Grawe RW, Falloon IRH, Widen JH, Skogvoll E (2006). Two years of continued early treatment for recent-onset schizophrenia: a randomized controlled study. Acta Psychiatrica Scandinavica 114/5, 328-336.

Green AI, Tohen MF, Hamer RM, Strakowski SM, Lieberman JA, Glick I, Clark WS (2004). First episode schizophrenia-related psychosis and substance use disorders: acute response to olanzapine and haloperidol. Schizophrenia Research 66, 125-135.

Horan WP, Subotnik KL, Snyder KS, Nuechterlein KH (2006). Do recent-onset schizophrenia patients experience a 'social network crisis'? Psychiatry: Interpersonal and Biological Processes 69, 115-129.
International Early Psychosis Association Writing Group (2005). International clinical practice guidelines for early psychosis. British Journal of Psychiatry, 187(48), s120-s124.

Jackson C, Knolt C, Skeate A, Birchwood M (2004). The trauma of first episode psychosis: the role of cognitive mediation. Australian and New Zealand Journal of Psychiatry 38, 327-333.

Knapp M, Mangalore R, Simon J (2004). The global costs of schizophrenia. Schizophrenia Bulletin 30, 279-293.

Koreen AR, Siris SG, Chakos M, Alvir J, Mayerhoff D, Lieberman J (1993). Depression in first-episode schizophrenia. American Journal of Psychiatry, 150, 16431648.

Kreyenbuhl J, Buchanan RW, Dickerson FB, Dixon LB and The schizophrenia patient outcomes research team (PORT) (2010). Updated treatment recommendations 2009. Schizophrenia Bulletin 36, 94-103.

Kuipers E (2001). Needs of carers. In Measuring Mental Health Needs (ed. GH Thornicroft), pp. 342-362. Gaskell Press: Glasgow.

Kuipers E (2007). Psychological therapies for schizophrenia: family and cognitive interventions. Psychiatric Times XXIV(2).

Kuipers E (2010). Time for a separate psychosis caregiver service? Journal of Mental Health 19, 401-404.

Kuipers E, Bebbington P (2005). Research on burden and coping strategies in families of people with mental disorders: problems and perspectives. In Families and Mental Disorder: From Burden to Empowerment (ed. N. Sartorious, J. Leff and J. J. Lopez), pp. 217-234. Wiley: Chichester.

Kuipers E, Leff J, Lam D (2002). Family Work for Schizophrenia: A Practical Guide, 2nd edn. Gaskell: London.

Kuipers E, Onwumere J, Bebbington P (2010). A cognitive model of caregiving in psychosis. The British Journal of Psychiatry 196, 259-265.

Kuipers E, Raune D (2000). The early development of expressed emotion and burden in the families of first onset psychosis. In Early Intervention in Psychosis (ed. M. Birchwood, D. Fowler and C. Jackson), pp. 128-140. John Wiley \& Sons: Chichester.

Lambert M, Conus P, Lubman DI, Wade D, Yuen H, Moritz S, Naber D, McGorry PD, Schimmelmann BG (2005). The impact of substance use disorders on clinical outcome in 643 patients with first-episode psychosis. Acta Psychiatrica Scandinavica 112, 141-148.

Leavey G, Gulamhussein S, Papadopoulos C, Johnson-Sabine E, Blizard B, King M (2004). A randomized controlled trial of a brief intervention for families of patients with a first episode of psychosis. Psychological Medicine 34, 423-431.

Lenior ME, Dingemans PM, Linszen DH (2001). Social functioning and the course of early-onset schizophrenia: five year follow-up of a psychosocial intervention. British Journal of Psychiatry 179, 53-58.

Lieberman JA, Fenton WS (2000). Delayed detection of psychosis: Causes, consequences, and effect on public health. American Journal of Psychiatry 157, 1727-1730. 
Lieberman JA, Tollefson G, Tohen M, Green AL, Gur RE, Kahn R, McEvoy J, Perkins D, Sharma T, Zipursky R, Wei H, Hamer RM, and the HGDH Study Group (2003). Comparative efficacy and safety of atypical and conventional antipsychotic drugs in first-episode psychosis: a randomized, double-blind trial of olanzapine versus haloperidol. American Journal Psychiatry 160, 1396-1404.

Linszen D, Dingemans P, VanderDoes JW, Nugter A, Scholte P, Lenior R, Goldstein MJ (1996). Treatment, expressed emotion and relapse in recent onset schizophrenic disorders. Psychological Medicine 26, 333-342.

Loughland CM, Lawrence G, Allen J, Hunter M, Lewin TJ, Oud NE, Carr VJ (2009). Aggression and trauma experiences among carer relatives of people with psychosis. Social Psychiatry \& Psychiatric Epidemiology 44, 1031-1040.

Lowenstein JA, Butler DW, Ashcroft K (2010). The efficacy of a cognitively orientated carers group in an early intervention in psychosis service-a pilot study. Journal of Psychiatric and Mental Health Nursing 17(7), 628-635. doi: 10.1111/j.1365-2850.2010.01564.x.

Macdonald EM, Hayes RL, Baglioni AJ (2000). The quantity and quality of the social networks of young people with early psychosis compared with closely matched controls. Schizophrenia Research 46, 25-30.

MacDonald E, Sauer K, Howie L, Albiston D (2005). What happens to social relationships in early psychosis? A phenomenological study of young people's experiences. Journal of Mental Health 14, 129-143.

Mackrell L, Lavender T (2004). Peer relationships in adolescents experiencing a first episode of psychosis. Journal of Mental Health 13, 467-479.

MacInnes D (2000). Relatives and informal caregivers: In: Chaloner C, Coffey M, eds. Forensic Mental Health Nursing: Current Approaches Blackwell Science, Oxford, 208, 208-31.

Magliano L, Marasco C, Fiorillo A, Malangone C, Guarneri M, Maj M (2002). The impact of professional and social network support on the burden of families of patients with schizophrenia in Italy. Acta Psychiatrica Scandinavica 106, 291-298.

Magliano L, Fiorillo A., De Rosa C, Malangone C, \& Maj M (2005). Family burden in long-term diseases: a comparative study in schizophrenia vs. physical disorders. Social Science $\mathcal{E}$ Medicine, 61(2), 313-322.

Mari JJ, Striener DL (1994). An overview of family interventions and relapse on schizophrenia: meta-analysis of research findings. Psychological Medicine 24, 565-578.

McCann TV, Luban DI \& Clark E (2011). First time primary caregivers' experience of caring for young adults with first episode psychosis. Schizophrenia Bulletin 37(2) 381-388.

Mihalopoulos C, Magnus A, Carter R, Vos T (2004). Assessing cost-effectiveness in mental health: family interventions for schizophrenia and related conditions. Australian and New Zealand Journal of Psychiatry 38, 511-519.

Mueser KT, Rosenberg SR (2003). Treating the trauma of first episode psychosis: A PTSD perspective. Journal of Mental Health 12, 103-108.

National Institute for Clinical Excellence (2009). Schizophrenia (Update). Clinical Guidelines CG82. NICE (http://www.guidance.nice.org.uk/CG82).
Nielssen O, Large M (2010). Rates of homicide during the first episode of psychosis and after treatment: a systematic review and meta-analysis. Schizophrenia Bulletin 36(4), 702-712. doi: 10.1093/schbul/sbn144.

Nordstrom A, Kullgren G (2003a). Victim relations and victim gender in violent crimes committed by offenders with schizophrenia. Social Psychiatry and Psychiatric Epidemiology 38, 326-330.

Nordstrom A, Kullgren G (2003b). Do violent offenders with schizophrenia who attack family members differ from those with other victims? International Journal of Forensic Mental Health 2, 195-200.

Norman RMG, Malla AK (2001). Duration of untreated psychosis: a critical examination of the concept and its importance. Psychological Medicine 31, 381-400.

Norman RMG, Malla AK, Verdi MB, Hassall LD, Fazekas C (2004). Understanding delay in treatment for first episode psychosis. Psychological Medicine 34, 255-266.

Onwumere J, Kuipers E, Bebbington P, Dunn G, Fowler D, Freeman D, Watson P, Garety P (2008). Care-giving and illness beliefs in the course of psychotic illness. Canadian Journal of Psychiatry 53, 460-468.

Onwumere J, Kuipers E, Bebbington P, Dunn G, Freeman D, Fowler D, Garety P. Coping styles in carers of people with recent and long-term psychosis. Journal of the Nervous and Mental Disease (in press).

Parabiaghi A, Lasalvia A, Bonetto C, Cristofalo D, Marrella G, Tansella M, Ruggeri M (2007). Predictors of changes in caregiving burden in people with schizophrenia: a 3-year follow-up study in a community mental health service. Acta Psychiatrica Scandinavica 116(s437), 66-76.

Patterson P, Birchwood M, Cochrane R (2005). Expressed emotion as an adaptation to loss - Prospective study in first-episode psychosis. British Journal of Psychiatry 187, S59-S64.

Pharoah F, Mari J, Rathbone J, Wong W (2010). Family intervention for schizophrenia. Cochrane Database of Systematic Reviews (12), Art. No.: CD000088. doi: 10.1002/14651858.CD000088.pub3

Pilling S, Bebbington P, Garety P, Kuipers E, Geddes J, Martindale B (2002). Meta-analysis of psychological treatment in psychosis I: family work and individual CBT. Psychological Medicine 32, 763-782.

Raune D, Kuipers E, Bebbington P (2004). EE at first episode psychosis: investigating a carer appraisal model. British Journal of Psychiatry 184, 321-326.

Robinson J, Harris MG, Harrigan SM, Henry LP, Farrelly S, Prosser A, Schwartz O, Jackson H, McGorry PD (2010). Suicide attempt in first-episode psychosis: A 7.4 year follow-up study. Schizophrenia Research 116, $1-8$.

Rotondi AJ, Anderson C, Haas GL, Eack SM, Spring MB, Ganguli R, Newhill C, Rosenstock J (2010). Web based psychoeducational intervention for persons with schizophrenia and their supporters: one year outcomes. Psychiatric Services 61, 1099-1105.

Sawatzky JE, Fowler-Kerry S (2003). Impact of caregiving: Listening to the voice of informal caregivers. Journal of Psychiatric and Mental Health Nursing 10, 277-286. 
Schooler N, Rabinowitz J, Davidson M, Emsley R, Harvey PD, Kopala L, McGorry PD, Van Hove I, Eerdekens M, Swyzen W, De Smedt G, the Early Psychosis Global Working Group (2005). American Journal of Psychiatry 162, 947-953.

Stanghellini G, Ballerini M (2007). Criterion B (social dysfunction) in persons with schizophrenia: the puzzle. Current Opinion in Psychiatry 20, 582-587.

Stefan M, Travis M, Murray RM (2002). An Atlas of Schizophrenia. The Partenon Publishing Group: London.

Tennakoon L, Fannon D, Doku V, O'Ceallaigh S, Soni W, Santamaria M, Kuipers E, Sharma T (2000). Experience of caregiving: relatives of people experiencing a first episode of psychosis. British Journal of Psychiatry 177, 529-533.

Van Mastrigt S, Addington J, \& Addington D (2004). Substance misuse at presentation to an early psychosis program. Social Psychiatry and Psychiatric Epidemiology, 39 (1), 69-72.

World Health Organisation (2001). World Health Report. Mental Health: New Understanding, New Hope. World Health Organisation: Geneva.

Zhang M, Wang M, Li J, Phillips MR, (1994).

Randomised-control trial of family intervention for 78 first-episode male schizophrenic patients. British Journal of Psychiatry 165 (Suppl. 24), 96-102. 